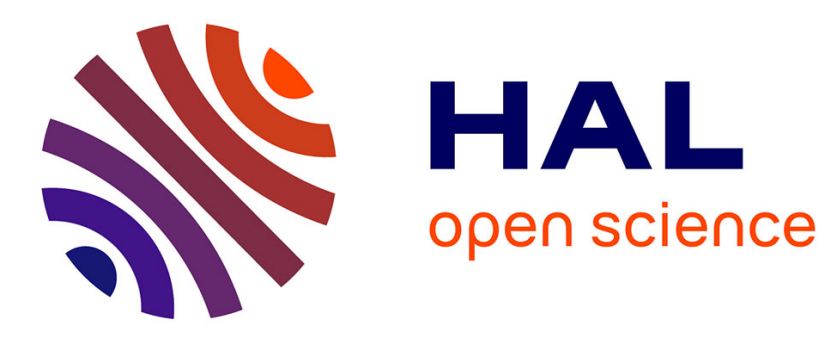

\title{
Assessing Energy Strategies in Active Buildings considering Human Behaviour
}

Ayesha Kashif, Stéphane Ploix, Julie Dugdale

\section{To cite this version:}

Ayesha Kashif, Stéphane Ploix, Julie Dugdale. Assessing Energy Strategies in Active Buildings considering Human Behaviour. International Symposium on Sustainable Human-Building Ecosystems, Oct 2015, Pittsburgh, United States. hal-02091649

\section{HAL Id: hal-02091649 https://hal.science/hal-02091649}

Submitted on 5 Apr 2019

HAL is a multi-disciplinary open access archive for the deposit and dissemination of scientific research documents, whether they are published or not. The documents may come from teaching and research institutions in France or abroad, or from public or private research centers.
L'archive ouverte pluridisciplinaire HAL, est destinée au dépôt et à la diffusion de documents scientifiques de niveau recherche, publiés ou non, émanant des établissements d'enseignement et de recherche français ou étrangers, des laboratoires publics ou privés. 


\author{
Assessing Energy Strategies in Active Buildings considering Human Behaviour \\ Ayesha Kashif $^{1,2}$, Stephane Ploix ${ }^{1}$, Julie Dugdale ${ }^{2}$ \\ ${ }^{1}$ G-SCOP lab / Grenoble Institute of Technology, \\ 46 Avenue Felix Viallet, 38031 Grenoble, France; email: ayesha.kashif@g-scop.inpg.fr, \\ stephane.ploix@grenoble-inp.fr \\ ${ }^{2}$ LIG lab / University of Grenoble, \\ 110, Av de la Chimie, 38400, Saint Martin d'Hères, France; email: julie.dugdale@imag.fr
}

\begin{abstract}
In the recent years, surveys and studies have established the importance of occupant's behaviour on energy consumption in buildings. Therefore, inclusion of inhabitants' behaviours is compulsory for the assessment of building energy management system's (BEMS) strategies, which highly depends on human behaviour. The purpose of modelling the inhabitants behaviour is to see how their choices and control of household appliances can impact the energy consumption. In this paper, a cosimulation approach is presented where the inhabitants' behaviours are co-simulated with the SIMBAD-MOZART thermal model of a reference house and BEMS. The realization of all the different kinds of inhabitant behaviours into energy co-simulations will help to improve the smart grid technology and hence provide inhabitants with better services to save energy and cost while maintaining their comfort levels.
\end{abstract}

\title{
INTRODUCTION
}

The advancements in the electric grid technology have led to the concept of a smart grid that uses the information technology to communicate with the suppliers and customers about their energy supply and demand needs. The smart grid helps in improving energy efficiency and sustainability of its production and distribution. The information that can be provided to the inhabitants consists of availability of energy, tariff details and energy consumption by different household appliances etc. After receiving all the different information from the smart grid, the inhabitants must be intelligent enough to interpret all this information so that they can save energy while maintaining their comfort. This requires a high cognitive workload to make decisions about energy management, and the results depend on how intelligently the information is handled and acted upon. The intelligent systems called Building Energy Management System (BEMS) are under development [Doukas et al., 2007]. They control the environmental conditions inside the house such that its less costly and more comfortable for the inhabitants. The inhabitants can also communicate with the BEMS and can express their comfort needs, occupancy plans etc. and can also ask for advice. In order to assess and evaluate the different strategies that are developed by the BEMS, it is important to include the inhabitants reactive and dynamic interactions with their environment in building energy simulations. It will help to analyze the control of different 
behaviours over the environment and the resulting impact on energy consumption patterns. Similarly, the role of BEMS in the presence of these reactive behaviours will be more challenging and will lead to improved functionality and energy efficient decision making. The BEMS used in the co-simulation called G-HomeTech [Ha et al., 2012] has been developed at G-SCOP and commercialized by Vesta System [VestaEnergy, 2011].

\section{INHABITANTS' BEHAVIOUR MODEL}

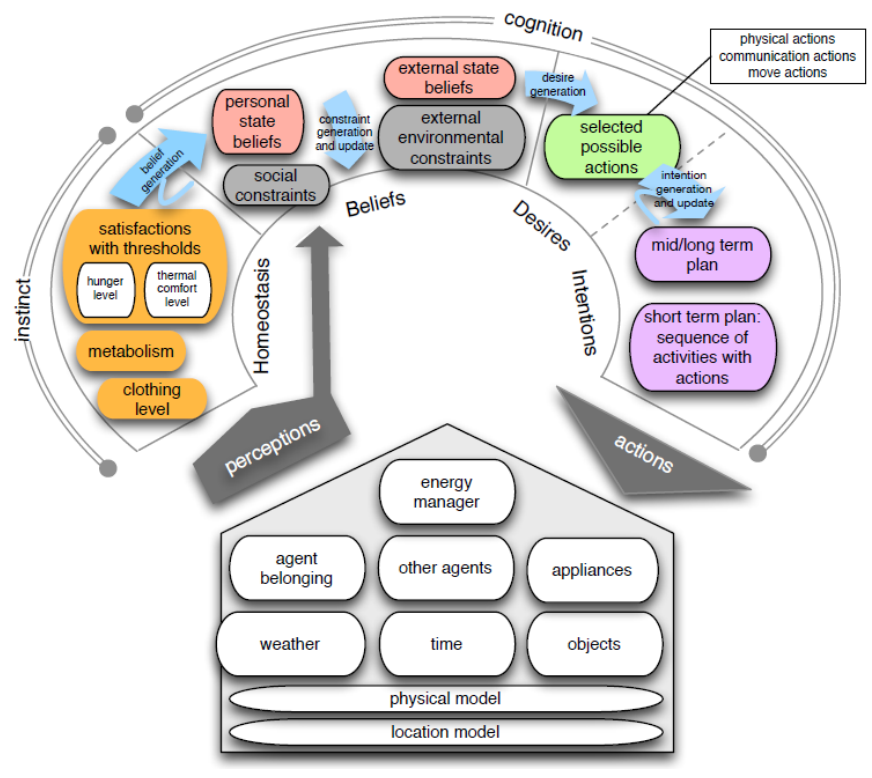

Figure 1: H-BDI dynamic behaviour representation model

In this paper, different elements that constitute the inhabitants' behaviour for energy management are combined to build a global H-BDI model (figure 1). This model is based on the BDI (belief, desire, intention) architecture [2]. However, the notion of homeostasis is introduced to capture the physical behaviour of human body. Figure 1 shows the cycle of inhabitants' behaviour that starts with perception of the environment, passes through the instinctive and cognitive phases and ends up with actions back on the environment. The outside environment includes the location, physical building models, the objects, appliances, and other agents etc. All these environmental elements are then perceived by the agent. Upon the perception the agent will translate these elements as its beliefs, shown by the "Beliefs" part of the cycle. In the model in figure 1, however, another concept is introduced in addition to beliefs that relates to the internal physical state of an inhabitant e.g. hunger level based on metabolism. Based on the beliefs about homeostasis and the outside environment the agent can have certain desires, however, due to the external environmental constraints only one of them is converted to the agent's intention. Finally, based on the intention the agent performs certain actions on the environment. 


\section{CO-SIMULATION ENVIRONMENT}

Reactive and deliberative behaviour models of inhabitants can easily be implemented with a multi-agent approach [4] and [3]. The same multi-agent approach is used to co-simulate the inhabitants dynamic behaviour with BEMS that will help to analyse the strategies developed by BEMS in the presence of occupants in the house. This section presents the co-simulation of inhabitants' behaviour with the thermal model, SIMBAD, of a reference building, MOZART [5] and the Building Energy Management System (BEMS) G-HomeTech. The objective is to analyse the impact of building energy management system to save energy in the presence of inhabitants' reactive and dynamic decision making behaviour on household appliances. A comparison is also made to analyse the impact of different behaviours (Eco, Non Eco) on the energy consumption and thermal comfort levels with and without the presence of BEMS. The notion of comfort in the inhabitants is introduced using the Fanger's comfort model [1].

The thermal model for this house called the SIMBAD-MOZART model was built in Matlab/Simulink by CSTB (Centre Scientifique et Technique du Batiment). SIMBAD-MOZART calculates the temperature in each zone by taking into account various input variables. Some of the most important variables, shown inside the yellow rectangle in figure 2, include the power of all the different appliances present in the zone, the position of the blinds e.g. open/closed, number of occupants in the zone, respiration flow rate, weather data, artificial lighting, and ventilation. The impact of window states (opened/closed) is also taken into account through ventilation, i.e. the air mass flow between the inside and outside of the building.

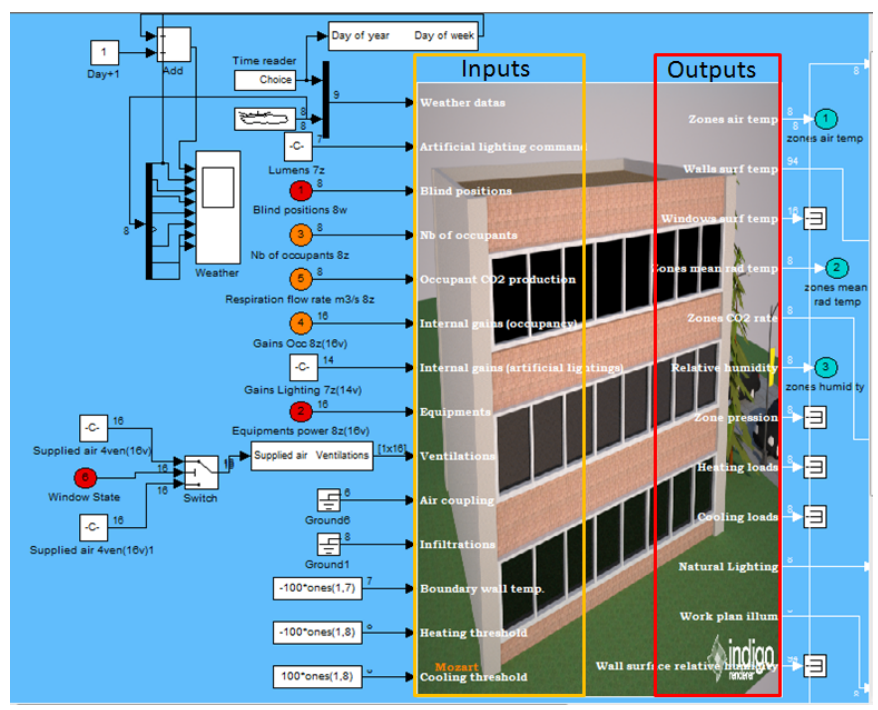

Figure 2: SIMBAD-MOZART thermal model

The Brahms-SIMBAD-G-HomeTech co-simulation environment is shown in figure 3. The Brahms-BEMS-Interface module provides the interconnection of SIMBAD thermal model with both the BEMS and the Brahms multi-agent simulation environment [6]. The input that goes to this module from the SIMBAD thermal model is 
the air temperature, mean radiant temperature and humidity. Other inputs include the electric power of appliances, the setpoint temperature and the appliance mode (on/off). The BEMS will use these variables to compute the energy plan and to control the appliances. Conversely, in Brahms these variables are perceived by the agents, who further take certain actions to control their thermal environment. The output from this interface module either comes from the Brahms simulation environment or the BEMS. The output from Brahms simulation environment consists of occupancy data in each room in the house and the status/modes (on/off, open/closed) of all household appliances or objects. Similarly, the output from the BEMS consists of the setpoints and appliance modes.

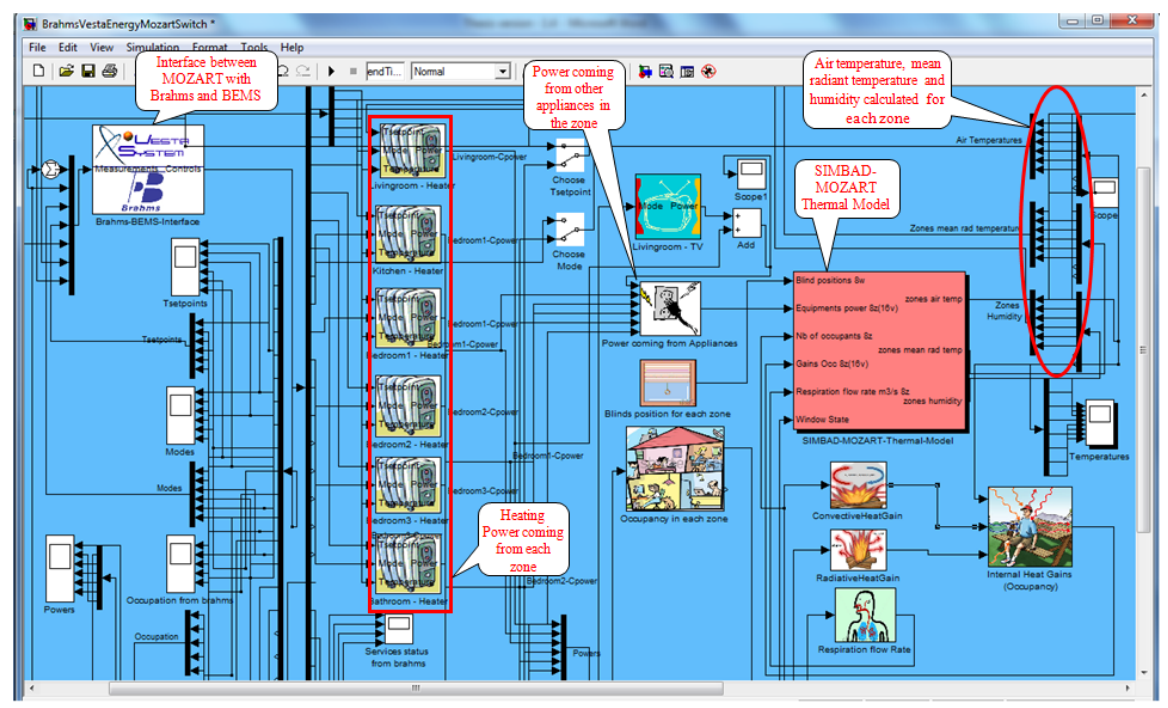

Figure 3: Co-simulation environment

The SIMBAD-MOZART-Thermal-Model module in figure 3 continuously perceives the values coming from either the BEMS or the Brahms simulation environment and calculates the new temperature at each simulation step. MOZART house is further used for developing a scenario of inhabitants' presence and their activities. The purpose of modelling the inhabitants' behaviour is to see how their choices and control of household appliances can impact the energy consumption.

\section{CO-SIMULATION SCENARIO AND RESULTS}

A scenario of a 2 person family, husband and wife, has been implemented in Brahms. The husband is an "Eco agent", whereas the wife is a "Non-eco" agent. After spending their day at work, the agents come back home in the evening. As the house is relatively warmer than outside, the agents will perceive it to be comfortable for a while. However, after a short period they will start perceiving that the actual temperature is very low. The comfort/discomfort of an agent is based on the homeostasis which further depends on the perceived PMV (Predictive Mean Vote) values in this scenario. As soon as an agent starts to feel warm (PMV 1 to 2), it takes some action to be comfortable 
again. However, if it does not take any action or if the action does not result the agent being comfortable again it will start feeling hot (PMV 2 to 3) or too hot (above 3). Similarly, as soon as the agents start perceiving negative PMV value, they increase the temperature setpoint to be warmth.

Since their perception of comfort does not solely depend on the temperature, but also on other factors, i.e. what activity they are involved in, what clothes they are wearing etc. The time at which they feel comfortable varies. As soon as an agent starts to feel warm it will take an action to be comfortable again. The EcoHusband agent would prefer to decrease the temperature by removing extra clothing and turning off the heater whereas the NonEcoWife agent would like to open the window to quickly become comfortable, without caring that the heater that is still working and that it is wearing too many clothes. The information about the control over the appliance/object is sent to the SIMBAD thermal model, where the new temperature for the room is calculated and sent back to Brahms. Based upon the new temperature the PMV values for all the agents are again calculated.

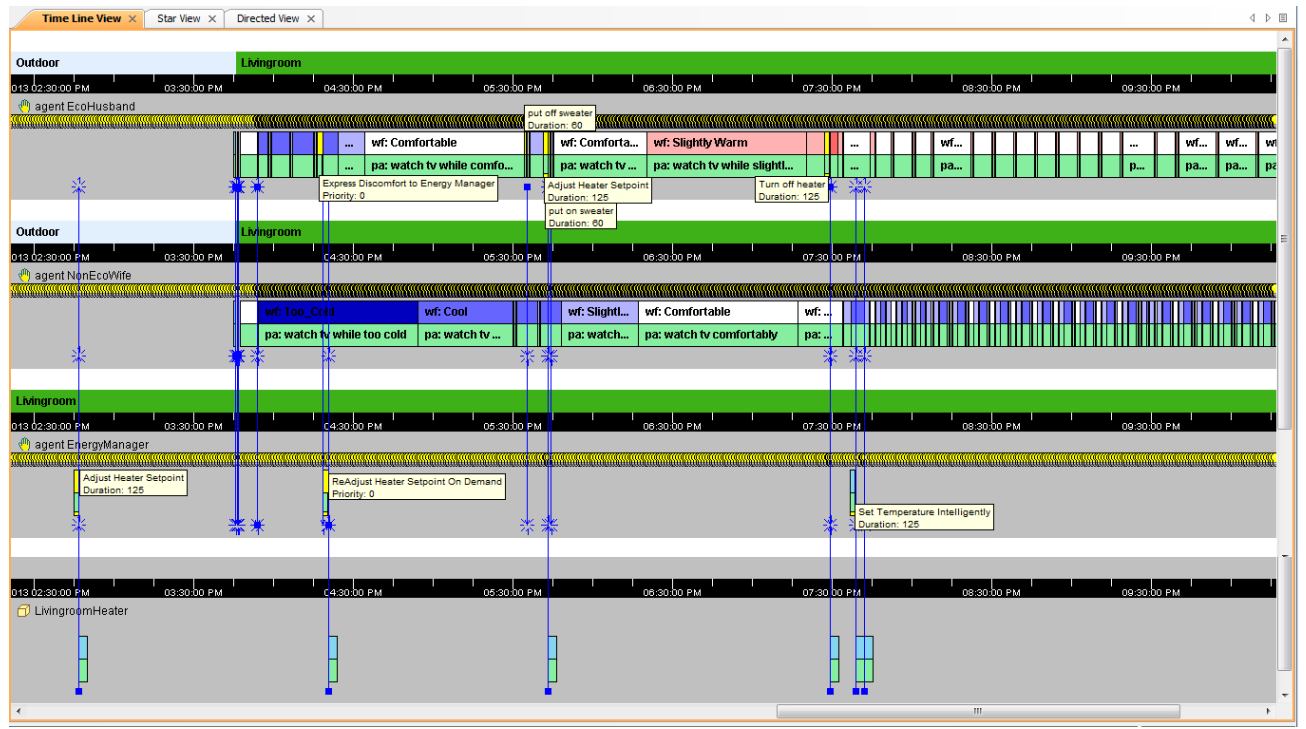

Figure 4: Brahms simulation: inhabitant's behaviour and BEMS's control over environment

Figure 4 shows a situation where the BEMS turned on the heater an hour before the agents enter the living room, shown by the yellow coloured workframes at around 15:00 in EnergyManager's space. The reason for this is that energy tariff is low at this hour of this day. The EcoHusband agent expressed discomfort to BEMS and BEMS adjusted the heater to a new value. This communication is shown by the yellow coloured workframes at around 16:20 in EcoHusband and EnergyManager's workspace. This time however, when the BEMS increased the temperature and EcoHusband agent started feeling comfortable, it removed its sweater, shown by "put off sweater" tool tip at this workframe around 17:30. This caused him to be uncomfortable with the setpoint adjusted by the BEMS and it did not communicate to the BEMS. It rather itself increased the setpoint to a higher value and put on the sweater. This 
is shown by the "Adjust Heater Setpoint" tool tip and "put on sweater" tool tips on theis workframe in EcoHusband's space at around 17:40. The blue line going from this workframe to the workframe in LivingroomHeater's space shows that the EchoHusband agent directly controlled the heater without any intervention by the energy manager. These actions helped the agent to become comfortable shown by the yellow coloured upward arrow showing the jump from one thermal condition to another in figure $5 \mathrm{c}$ at around 18:00. The temperature further went up to $26^{\circ} \mathrm{C}$, shown in figure $5 \mathrm{~b}$ at around 19:30. Now again it starts feeling warm and turns off the heater. At this point when the temperature starts decreasing, the BEMS interrupts the agents' decisions and does not let the temperature fall below $23^{\circ} \mathrm{C}$ by controlling the heating system. The state of the heater is shown in figure 5a under "LivingroomHeater State" where the signal first goes to zero and then to one due to BEMS interruption. This is shown by the "Set Temperature Intelligently" tool tip in EnergyManager's workspace at around 19:30. Thus the EcoHusband agent remains comfortable with the decision taken by the BEMS shown by the green curve in figure 5c between 20:00 and 23:00. The temperature when controlled by the BEMS, also helps NonEcoWife agent to remain in the slightly cool to comfortable condition rather than being cool or cold (figure 5c, 5d). This is shown by the light blue and white workframes in NonEcoWife's space in figure 4 and by the light blue and green curve in figure 5d between 20:00 and 23:00.

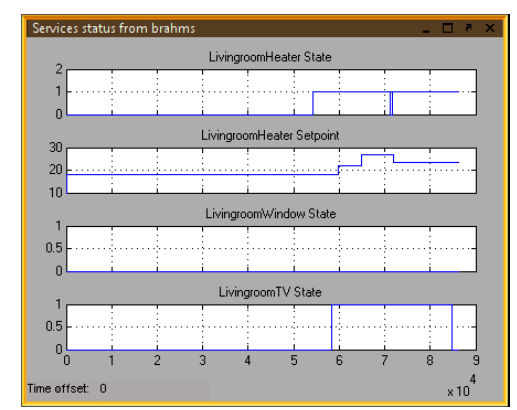

(a) Agent controls heater with BEMS

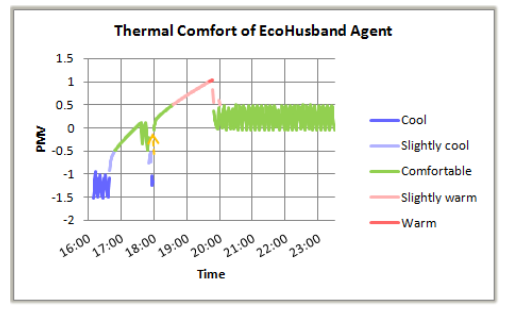

(c) PMV perceived by EcoHusband agent

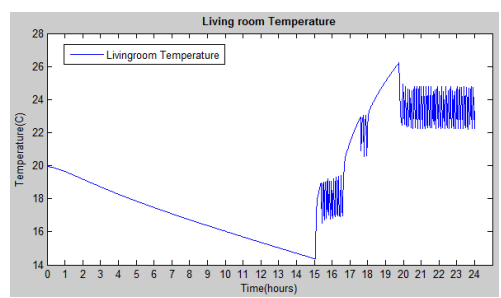

(b) Temperature controlled by agent and BEMS

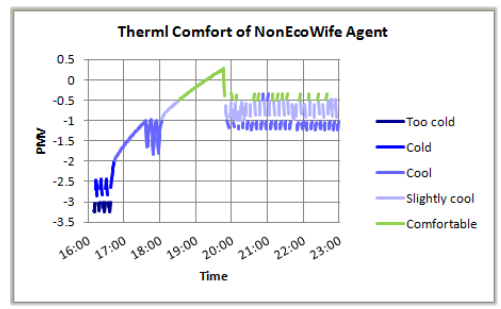

(d) PMV perceived by NonEcoWife agent

Figure 5: State of the appliance/object, temperature, and PMV perceived during simulation with BEMS 


\section{COST AND COMFORT ANALYSIS}

In this section, an analysis of the cost-comfort tradeoff for the situations with and without the BEMS is given. To quantify the comfort of agents, the PMV values obtained after the simulation runs are summed up for different PMV levels (figure 6a, $6 b)$. Since EcoHusband agent is not only concerned by the comfort but also the energy savings and in this effort it remains less comfortable than NonEcoWife agent (figure 6a). Mostly, it remains in slightly cool or slightly warm due to having more interactions with the heater to control the temperature. NonEcoWife agent, however, remains more comfortable than EcoHusband agent, as it is not concerned about energy savings and wants to achieve comfort at any cost. Figure $6 \mathrm{~b}$ shows the thermal comfort durations of agents with the inclusion of a BEMS in the system. In this case, the divergence of agents' comfort levels is reduced and they converge to the comfortable zone. Also, the agents remain comfortable for a longer time duration as compared to before i.e. without BEMS. In this case EcoHusband agent's comfort is better than NonEcoWife agent. The improvement in the comfort is due to the better decisions taken by the BEMS based on the knowledge that the BEMS has about the internal and external environmental conditions, weather forecasts, inhabitant's comfort and self learning algorithms. Figure 7

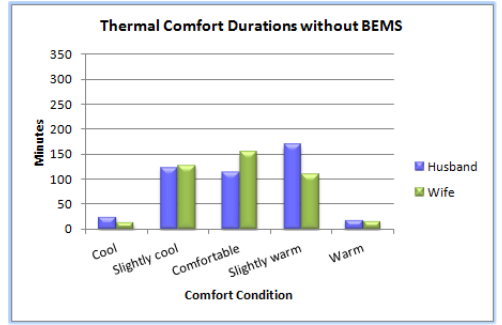

(a) Agents' thermal comfort without BEMS

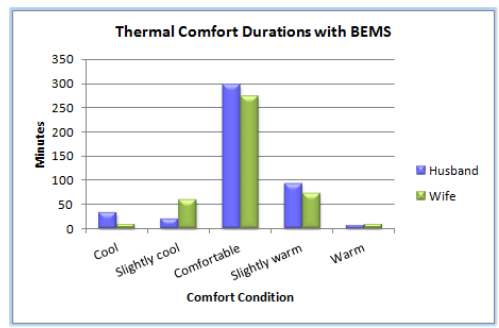

(b) Agents' thermal comfort with BEMS

Figure 6: Comfort of agents: with and without the control of BEMS

shows the power consumption of the electric heater while the environment is controlled by different agents with and without the BEMS. The highest power consumed is due to the behaviour of NonEcoWife agent since it tries to achieve comfort by opening and closing the window. This assessment of BEMS when co-simulated with building system and inhabitants shows that the BEMS is capable of not only saving the inhabitants from cognitive workload but also of providing them with better comfort and energy savings.

\section{CONCLUSION}

The behaviour model in the co-simulator generates the profiles which are random and dynamic. As soon as the environmental variables change, they change agents beliefs and the system reacts in a different way than before. The introduction of inhabitants reasoning processes towards their actions on the physical environment will 


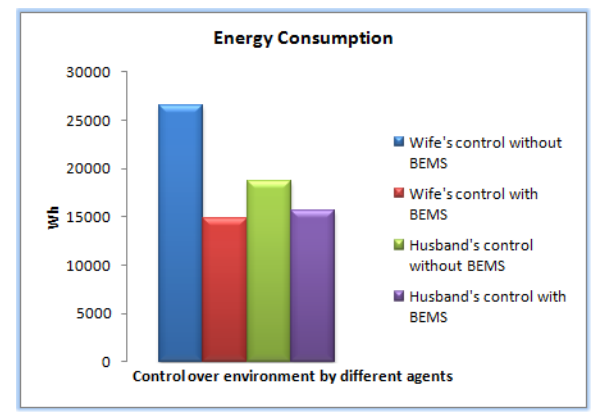

Figure 7: Energy consumed during control over environment by different agents with/without BEMS

give energy simulation tools more realism. The reactions to these grid signals could further be diverse and complex depending on different types of inhabitants e.g. based on their family composition, role in the family, economic conditions, knowledge and concerns about energy problem. The realization of all the different kinds of inhabitant behaviours into energy co-simulations with the smart grid will help to improve the smart grid technology and hence provide the inhabitants with better services to save energy and cost while maintaining their comfort levels.

\section{REFERENCES}

[1] FAnger, P. Assessment of mans thermal comfort in practice. British Journal of Industrial Medicine 30 (1973), 313-324.

[2] Georgeff, M., Pell, B., Pollack, M., Tambe, M., And Wooldridge, M. The belief-desire-intention model of agency. In Proceedings of 5th International Workshop on Intelligent Agents: Agent Theories, Architectures, and Languages (Heidelberg Germany, 1999), Springer-Verlag, pp. 1 - 10.

[3] Kashif, A., Dugdale, J., And Ploix, S. Simulating occupants' behaviour for energy waste reduction in dwellings: A multi agent methodology. Advances in Complex Systems 16 (2013), 37.

[4] Kashif, A., Ploix, S., Dugdale, J., And Le, X. H. B. Simulating the dynamics of occupant behaviour for power management in residential buildings. Energy and Buildings 56 (2013), 85-93.

[5] Noel, J. Cas d'exemple codyba a partir de la typologie cstb des batiments. http: //www.jnlog.com/pdf/typologie_cstb.pdf, 2008.

[6] Sierhuis, M., Clancey, W., And van Hoof, R. Brahms - a multiagent modeling environment for simulating work practice in organizations. International Journal of Simulation and Process Modelling 3(3) (2007), 134-152. 